\title{
A Comprehensive Analysis of DSTATCOM-Based Power Improvement
}

\author{
Vidhyavati Suryawanshi \\ Ph.D. Scholar \\ Electrical Engineering Department \\ Chandigarh University \\ Ajitgarh, Punjab, India \\ vidhya_vs2003@yahoo.com
}

\author{
Dr. Surbhi Gupta \\ Associate Professor \\ Electrical Engineering Department \\ Chandigarh University \\ Ajitgarh, Punjab, India
}

\begin{abstract}
Power quality became one of the most critical challenges in today's modern power system. Utmost primary factors of power quality issues are non-linear fluctuating loads, system interruption, load variances, infrequent loads, and arc furnaces. As a matter of fact, there is occurrence of various electrical distortions, along with voltage spikes, voltage sags, and so forth. Several innovative techniques were employed for the development of circuits which resulted in minimised voltage stability as well as reliability. Utility companies which are electrical are receiving a large quantity of complaints because of these challenges. An approach is required now to explore the power quality challenges in industrial sector, corporate sector, municipal, or domestic sites. Therefore, a few techniques known as Flexible AC transmission system (FACTs) are used to enhance power quality. It is divided into two categories: namely series-FACTs and shunt-FACTS. As name itself define its architecture that in series-FACTS comprised of transmission line which is connected in series with module and connected in parallel in shun-FACTs. We can alleviate the problems related to power quality with the help of these FACTS devices. DSTATCOM is one of the better devices available. D-STATCOM is a shunt-connected solid-state device employed at the distribution network to maintain load-side disturbances. It has exceeded the traditional capacitor being used improve power quality with it's lower upfront investment, outstanding dynamics, absence of static, and lower operational expenses. The sorts, architectural style, operating, control systems, and AI are all described in this article.
\end{abstract}

Keywords: AI, FACT system, D-STATCOM, AC.

\section{INTRODUCTION}

The three basic essential features of the electricity network are production, transmission, and allocation. Production units must generate an adequate amount of electricity, transmitting units must supply power throughout huge regions, and massive power systems must allocate electricity to every establishments of the user, according to powersystem consistency necessities. The power quality is measured by the condition of the allocation network, which is placed at the end of the electricity network and integrates directly to the users. One reason appears to be that breakdowns in the power distribution network account for $80 \%$ of all interruptions experienced by the general public. As a result, the distribution system is getting importance these days in terms of reliability, c. In classical AC transmitting network, the ability to transfer Ac supply is limited by a number of factors, including temperature constraints, dynamic load constraints, power boundaries, maximum voltage thresholds, and so on.

The highest quantity of electric power which can be proficiently transmitted over a transmitting system without inflicting suffering to electronics devices or power lines is specified by such constraints. This one is ordinarily achieved by altering the architectural style of the power system. This is not really feasible, then there is another method to realize optimal transfer efficiency and potential by not changing the structure of the power systems. Including the overview of changeable impedance equipment such as inductors and capacitors, a fraction of the electricity from the source is retained as reactive power in such elements and returned to the source, instead of being transferred to the loads.

This revealed that, the real power, or the amount of electricity sent to the load, has always been less than the perceived power, or overall power.

For best possible transmitting, the active power (ACP) must be equivalent to the apparent power (APP). To look at it in other pattern, the ratio of active power and apparent power (ACP/APP) power factor have to be one. A FACTS comes into the equation at this point.

The concept "flexible AC transmitting system" refers to a collection of electronic power as well as power system equipment that help in improving the allocation network manoeuvrability, durability, and transmitting abilities.

FACTS control systems are a progression in power electronics equipment. 


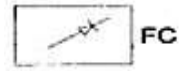

(a) General FACTS controller (FC)

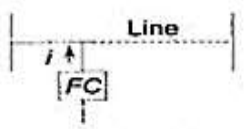

(c) Shunt controller

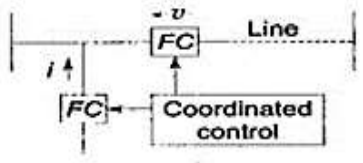

(e) Coordinated series and shunt controller

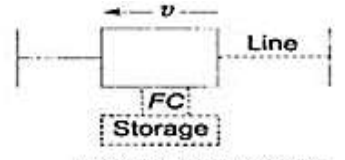

(b) Series controller

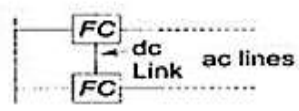

(d) Unified seriosserios controller

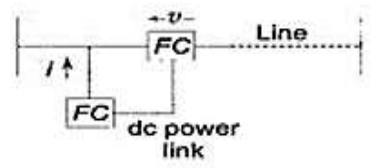

(f) Unified series: shunt controller
Fig.1 Categories of FACT Control Systems

The FACT system offers predictability and operability of the large electrical power portion of the network by incorporating power circuits to supply extremely high inductor and capacitor power into the affiliation.

There are four categories of Fact controllers:

1. Series-Type Fact control systems:

2. Shunt-Type Fact control systems:

3. Series- Shunt Type Fact control systems

4. Series- Series Type Fact control systems

As mentioned above, that the series-FACTs is the connection of transmission line and FACTs in series, and also defined that the shunt-FACT is the connection of transmission line and FACTs in parallel. When two Fact systems are attached in parallel including the DC transmission in a unified series control system. Which can be seen in Fig-1, completely separated equipment are employed to regulate voltage and current transmitting in organised sequence and unified series shunt control systems.

Benefits of shunt-connected over other are as follows:

1. It delivers dynamic potential controls

2. It offers the uninterrupted potential control

3. Improved stability, not any hysteresis, lesser operational, installation, and preservation expenses as equated to series controllers.

4. Active power control is practicable with a DSTATCOM, which supports in system constancy controller.

5. Over a inclusive voltage successions, the maximum reactive current may be attained.

6. It has very High productivity rate.

The allocating power static compensator is a significant and frequently employ shunt control system that is used to handle specific power quality issues such as voltage level, under voltage, and etc. The very first DSTATCOM was employed in 1999, and this was an SVC with Voltage Source Converter. It has exceeded the different kinds of control systems due to its lower upfront investment, outstanding consistency, absence of inertia, and cost reductions. DSTATCOM is often used to reimburse for reactive power in ac systems. The VSC controls the transmission of reactive power out from Dc voltage backup system to the Electrical network by using the leaky reactance of a transformer.

\section{LITERATURE REVIEW}

Sandeep Prajapati et al. [1] Numerous quality development methods for a distribution network of an electricity distribution line are highlighted in this section. Voltage starting to sag, voltage drips, and other quality defects are addressed. The voltage source converter (vsc) was employed by the DSTATCOM to transform direct voltage to three - phase power alternating voltage throughout the storage machine. The above power supply's amplitude and phase connectivity are modified that will provide the appropriate quantity of guiding or continue to lag reactive power for adjustment. This paper also highlights various control blocks. The simulation in MATLAB and various harmonic currents are also mentioned.

Pallavi et al. [2] Power quality problems in energy systems are highlighted in this section, that are mainly determined by pulsed loads that deteriorate throughput over a brief span of time. Such a story illustrates how DSTATCOM can be employed to reduce the impact of pulsed loads on a bus voltage and thus keep it stable, thereby enhancing power quality in an electrical network which involves both throughout and after pulsed loads. The DSTATCOM is a shunt-compensation equipment relies on a voltage-source inverter (VSI) that is widely employed in distribution networks in this manuscript to relieve power quality problems.

Trupti et al. [3] The control system and operation of the DSTATCOM are outlined in this scientific paper, with sine wave PWM and SVPWM as the control approaches for voltage. Harmonics and their disruption in all power quality control issues with SPWM and SVPWM have been spotted and enhanced as an outcome of this given research work. Thus to design and to simulate the framework, D-statcom employed the matlab/simulink toolkits.

Ktanuja et al. [4] This research article looks at the effectiveness, analyzation, and working principles of the distribution static compensator (DSTATCOM), a contemporary pattern of improved company hardware designed to ensure the overall effectiveness and survivability of voltage control in low voltage distribution networks, as well as the calculation of a d-STATCOM (distribution static 
compensator) used mostly for voltage sag remediation in transmission systems.

\section{DEVICE EXPLANATION}

\section{A. Meaning And Fundamental Overview Of D-STATCOM}

A voltage-controlled system namely STATCOM, that regulates the circulation of power through an electricity grid using force shunt- related equipment including IGBTs, GTOs, and many other force shunt-linked gadgets, and hence enhancing the network's consistency. STATCOM is a shunt gadget, that indicates it is shunt-connected to the line. Some other title for a STATCOM is a Static Synchronous Condenser. It's part of the FACTS (Flexible AC Transmission System) hardware group. The capacity to absorb the reactive power and also generate the reactive power in synchronisation with demand in way to sustain the voltage (V) and frequency grid consistent is referred to as "synchronized" in STATCOM.

A D-StatCom is similar to a STATCOM, with the exception that a STATCOM is employed at the transmission side to control fundamental reactive power as well as offering potential support, although a D-StatCom is employed at the distribution system to control voltage and compensate for reactive power. D-StatCom can remove THD, voltage dips, and rises. In addition, a D-StatCom could be used as a shunt improve converter to reduce supply power imbalances or disruptions. Figure 2 depicts the fundamental framework of a D-statcom, in which a power creating or allocation hub is linked to non-linear or fluctuating loads such as residences, office spaces, and other structures via a DSTATCOM parallel connected to a transmission line.

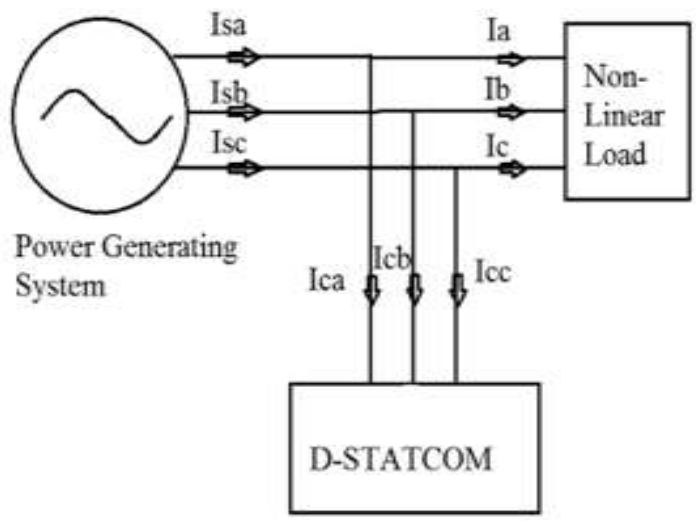

Fig. 2 Basic structure of D-STATCOM

\section{ARCHITECTURE}

The main architecture of a DSTATCOM comprise of the subsequent equipment:

1. Voltage Source Controller

2. Line Filter system including inductive, capacitive filter or also known as L-C filter

3. Transformer
4. Energy storing device

5. Control scheme block

VSC: The voltage source converter (VSC) transforms direct voltage into three-phase alternating voltage throughout the storage gadget. To provide the exact required amount of lead or lag reactive power, the amplitude and also the phase alignment of the supply is to be st appropriately. Three-phase, three-wire or three-phase, four-wire voltage source converters are available. Users can utilize a two-level converter or a three-level converter. It is a three-phase, two-level power converter that yields the desired voltage simulated outcomes. Diodes and a PWM are used to construct it.

Two commonly used VSC categories are described below.

A) Square shaped-wave Inverters employing Gate Turn-Off Thyristors: Because the core part of the converter, output voltage is directly proportionate to the DC voltage. The output $\mathrm{AC}$ voltage is regulated by varying the DC capacitor input voltage in this category of VSC.

B) PWM Inverters using Insulated Gate Bipolar Transistors (IGBT): It creates a sinusoidal waveform from a DC voltage source using the Pulse Width Modulation (PWM) methodology, by a classic chopping frequency of a few $\mathrm{kHz}$. The IGBT-dependent VSC, unlike the GTO-dependent category, deploys a constant DC voltage and modulates the output AC voltage by varying the modulation index of the Pulse width modulation scheme.

Harmonic or Line filters: In the DSTATCOM, numerous sorts of harmonic or line filtration systems are utilised depending on the input voltage. The sort of equipment to utilize and the presence of overtones at the output voltage identify the category of LC filter to employ. The LC filter is utilized to eliminate overtones and maintains the stability of the power output in converter.

Inductive Reactance or Transformer: The voltage source converter and the line filters works on the DC voltage. To match the type of voltage the output of the VSC after the filtering is connected with the coupling transformer which converts the DC voltage into required $\mathrm{AC}$ voltage connected with the line distribution.

The original objective of the energy storing system is to establish the inserted voltage by providing power to VSC via a dc link. The DC capacitor and the DC source are interconnected in parallel to store energy. It is the primary aspect responsible for storing reactive energy and transporting input ripple current. A battery system or a converter may be used to power this storing systems. 


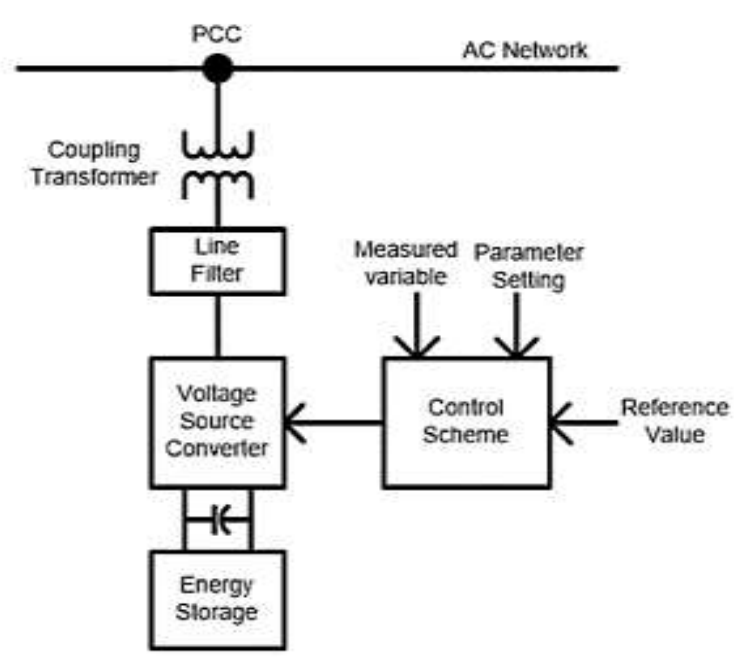

Fig-3 shows the architecture of the D-STATCOM.

Control Block: The voltage from the distribution side is subjected to various discrepancies, or faults, in the line. Every one of these faults, such as tends to lag, voltage sags, fluctuating voltages, and noise levels, are tried to correct in the Dstatcom's controller block. Inverters and a PWM are used to split the control systems into 2 components: master control and slave control. Hardware resources such as power electronic switching-devices and capacitor banks are affected by the controller blocks. Those certain controller blocks are constructed employing a wide range of available controlling hypotheses and techniques, including sequential park's concept and sequential frame theory.

The D-STATCOM's linkage to the distribution system is depicted in the figure 4 , as well as a transmission line with several loads and supply voltages. The D-STATCOM is connected to the transmission framework in parallel, as shown in Figure 3.4. Three separate lines are investigated in this schematic. These lines serve a variety of loads, including homes, offices, and industries. Whenever a fault occurs in the allocation side due to such loads, D-StatCom is connected at the interconnection to incorporate current into the device and dismiss the malfunction.

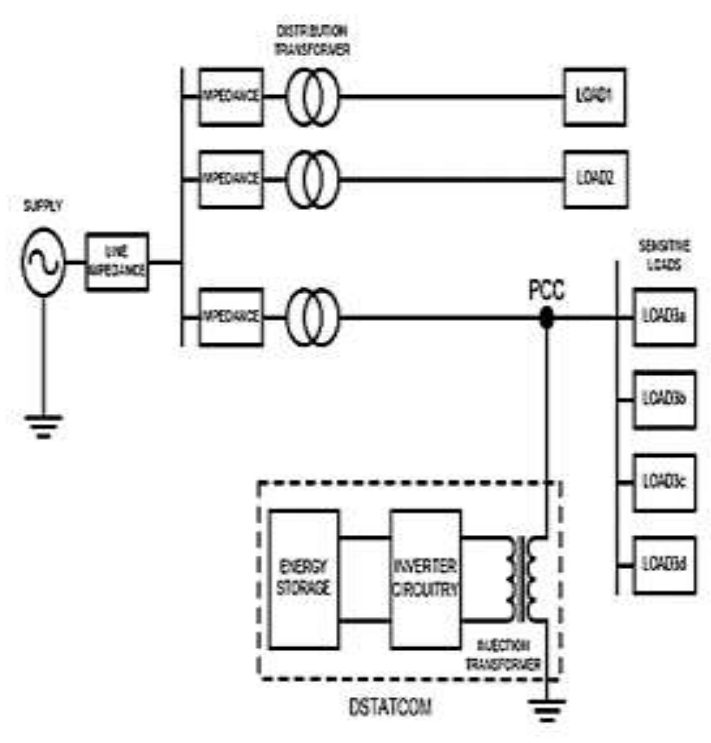

Fig. 4 shows the connection of the D-STATCOM with the transmission line or distribution network.

\section{A. Principle and Working ofaD-STATCOM}

The transformer, a capacitor for energy-storage, and control blocks make up the D-STATCOM. When the current or voltage created at the allocation site is lagging, it offers energy to the system; when the I or V produced is going to lead, it soaks up the energy of a system.

The transmission control protocol calculates and relates all the necessary voltages and currents to the instructions. The gadget then provides feedback control and generates a sequence of switching pulses in order to operate the power supply. Figure-5 depicts a DSTATCOM schematic in a single line.

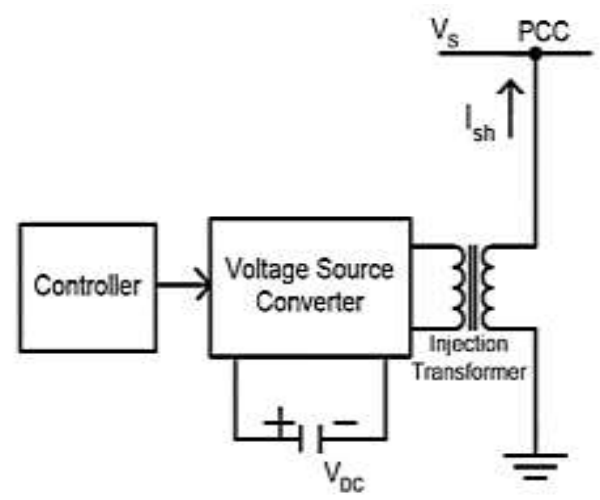

Fig. 5 single line schematic of a DSTATCOM converter

The Voltage Source Converters transforms DC supply into a sequence of 3-phase ac output voltages using Temperature sensors. The coupling transformer's reactance connects the above outputs to the AC system in process. To proficiently stabilise real and reactive power transition among the DSTATCOM as well as the main grid, the stage and 
magnitude of DSTATCOM output voltages are varied properly.

\section{B. InterchangeOf Reactive Power:}

The customizable amplitude of the DSTATCOM output power controls the aggressive power exchange of the DSTATCOM including the Alternating resource. The reactive power of the DSTATCOM is evaluated as follows:

$$
\mathrm{QP}=\frac{(V 0-V s) \cdot V s}{Z}
$$

Here QP is the reactive power. The DSTATCOM output voltage is namedas $\mathrm{VO}$

$\mathrm{Vs}$ is the valuation of the voltage supply. $\mathrm{Z}$ is the overall resistance provided by the capacitor $(\mathrm{C})$, resistor $(\mathrm{R})$, and inductors (I), if there is any, among DSTATCOM and the regulatory regime.

The reactive power exchange among DSTATCOM and the AC system is discussed in the following instances:

Case I: If the amplitudes of the DSTATCOM output voltage $\mathrm{Vi}$ and the $\mathrm{AC}$ system voltage $\mathrm{Vs}$ are equivalent, the value of reactive current is zero and also the DSTATCOM not absorb reactive power, as can be seen in Fig 6 .

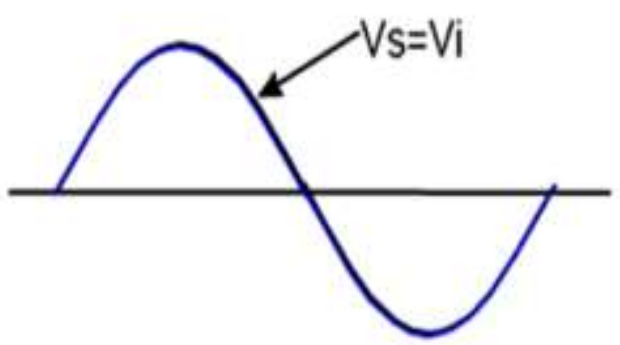

Fig. 6 Output and source voltage is in phase

(ii) The lag current circulates from the DSTATCOM towards the AC system via transformer reactance whenever the amplitude of the DSTATCOM output voltage is larger than the amplitude of the AC, PD power source, allowing the system to produce capacitive reactive power. All of that is depicted in

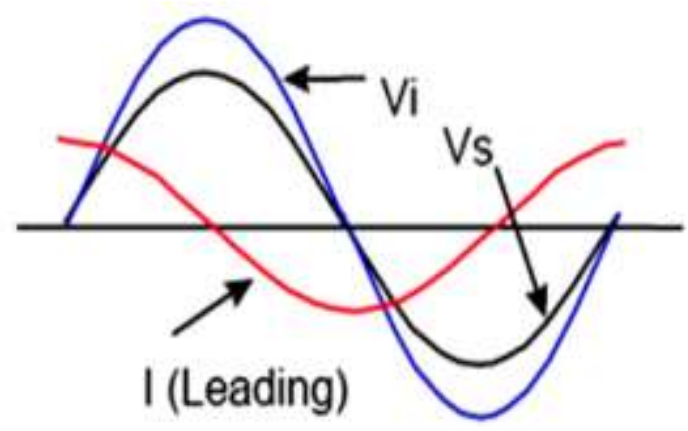

Fig. 7 Capacitive operation (iii) Once the amplitude of output voltage is minimized to a level less than that of the AC system, the going to lead current circulation from the $\mathrm{AC}$ system to the gadget, resulting in inductive reactive power. This is depicted in Figure 8

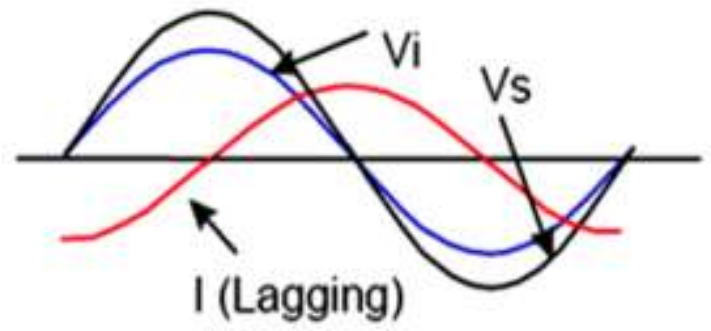

Fig. 8 Inductive operation

The Direct source condenser is required to deliver original power to the switching devices due to the increased use of switching devices. Genuine power transfer is required in direct voltage regulate to maintain the voltage of capacitor fixed. The V-I characteristic of the DSTATCOM is depicted in Figure 9. The DSTATCOM helps to control the voltage from V1 to V2 in a smooth and steady manner.

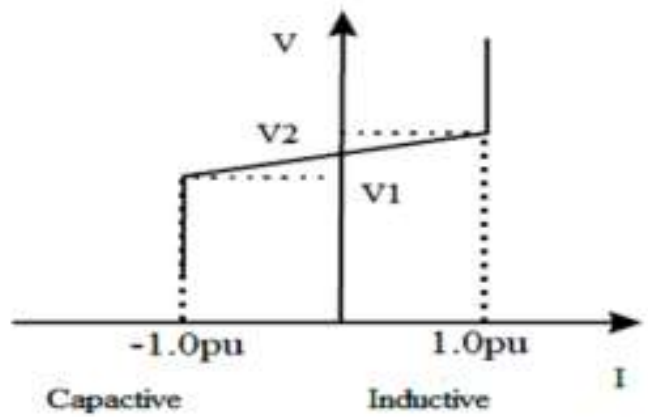

Fig. 9 V-I characteristics of DSTACOM

There is a genuine power transmission with the AC system if DSTATCOM is prepared through an external Dc voltage to regulate the voltage in the incident of extraordinarily low voltage in the electric grid or in the incident of breakdowns. The AC system will obtain real power from the capacitor or a DC source to maintain the voltage of the system at 1 p.u or 7. maintain the voltage of capacitor stable if the VSC output voltage is greater than the power source.

\section{Load Compensation in DSTACOM}

If the load is fluctuating or imbalance, the DSTATCOM's input voltage line produces a disrupted signal. This necessitates the use of a compensator to control the voltage. The DSTATCOM produces current to create the distorted current out from the line or positive load or in stage, which helps in the reduction of the impact. Load compensation is the name for this technique. The compensator offers a nearly one-to-one power factor. If II is the current of the load, the disrupted current is denoted as Id, \& Ids is represented for the STACOM current, therefore the KCL equation describes the 
load compensator current equation for the DSTATCOM as well as load at any node:

$\mathrm{I}_{\mathrm{c}}-\mathrm{I}_{\mathrm{ds}}=\mathrm{I}_{1}$

So it is concluded that the load compensator balances the current $\mathrm{I}_{1}$ for any disorders and noises.

\section{OPERATIONS PERFORMED By DSTATCOM}

DSTATCOMS used to correct the following type of inputs:

Sagging: At maximum frequencies, voltage sag is defined as a drop in the classic voltage supply among $10 \%$ and $90 \%$ of the traditional RMS (root mean square) voltage over time scales varying from 0.5 to $1 \mathrm{~min}$.
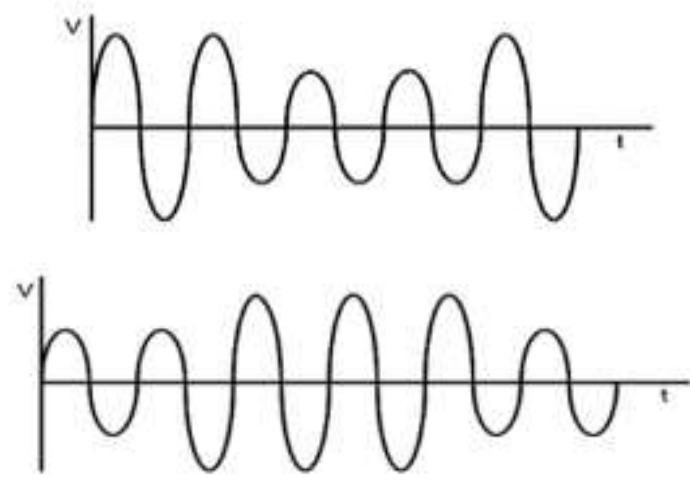

Fig-10a and b shows voltage sag and swells

When voltage sag takes place, the magnitude of the voltage is lowered, as shown in Figure 10. The connection of highvalued loads, the configuration of large motors, and deformities in the computer device are the leading reasons of voltage sag. Because the motor brings up to 10 times the peak valued load current at startup, starting large motor drives can result in a voltage drop. Voltage sag causes disconnections and decreased productivity in motor based mechanical devices, as well as breakdown of information systems hardware like micro-computer controllers.

\section{A. Voltage Swells}

A voltage swell is a concise increase in voltage at the power frequency that takes place at external sides of normal limits, lasts more than one cycle, and usually lasts only a few seconds. The magnitude of the voltage increase due to voltage swell is depicted in the diagram.

Voltage swell can be caused by line breakdowns, inadequately dimensioned sources of power, and incorrect tap setup in sub - station tap changers. An SLG breakdown could cause a voltage sharp rise in the balanced phases. It's possible that inspiring a large capacitor bank will result in swell. Lighting flickers, data disappears, and crucial frameworks come to a halt or are injured as a result of over voltages.

\section{B. Interruptions}

Whenever there is a concise but complete interruption of supply, it is called an interference. An interference takes place whenever the supply voltage falls by lower than $10 \%$ from its original value for a period of lower than 60 seconds. The number of supply interruptions increases voltage sag, that must be reduced. There are different types of interruptions, such as short and long interruptions.

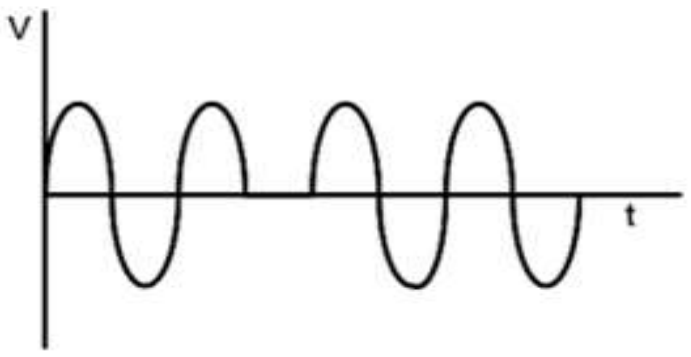

Fig. 11 shows interruptions

\section{Transients}

Transients are brief voltage variations lasting from a few micro-seconds to a few milli-seconds. Such variations can attain large numbers of volts though at low voltage. Transient response can be divided into two categories, that are explained below: An impetuous transient can be described as relatively short linear difference in voltage, current, or even both on a power line. An oscillating transient is a slight bi - directional variation in voltage, current, or even both on a power line. Power compensation capacitors, load depending on inductors swapping, and transformer ferro-resonance all contribute to such transients.

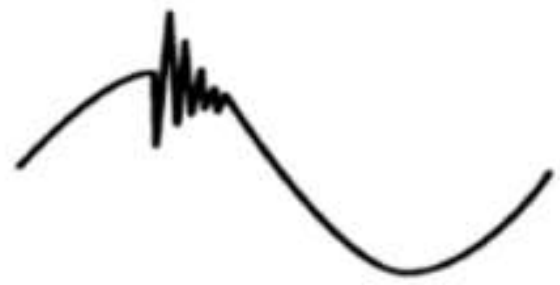

Fig-12 shows voltage transients

\section{Distortion of Harmonics}

Harmonic distortion is defined as the difference in between the ideal sinusoidal waveform and the waveform occurred from voltage supply. The interaction of distorted user loads and supplying network impedance causes it. The much more adverse reactions are the thermal expansion of induction motors, amplifiers, and capacitors, and even the over-loading of neutrals.

\section{Control of Dstacom:}

The control system is the backbone of the D-STACOM used for power system modifications, and the methodology used for control determines how it reacts to fluctuating changes in load. In the number of situations, the D-STATCOM power circuit is regulated in three stages. 
1. Phase shift control: The phase shift control scheme is simple and clear. The aim is to maintain a constant voltage at the output side. The controlling algorithm uses voltage angle control to generate a phase shift in the terminal voltage of voltage source controller with respect to the AC connected in series. A fault signal is generated whenever the evaluated PCC voltage is tried to compare to the destined voltage.

2. Carrier based PWM control: A stable power carrier relying sinusoidal Pulse Width Modulation is used to create the switching signal for carrierdepending Pulse Width Modulation control of the Voltage Source Controller switching device. The idea of spontaneously reactive power underpins the above technique. The loads, and also the instantaneous voltage and current of the established system, are all supervised.

3. Carrier less hysteresis control: The in-phase \& quadrature unit vectors are calculated by employing the terminal voltage. This compensation scheme is very versatile, which has been utilized for a wide range of implementations, including enhancing power factor, voltage control, balancing of load, harmonic suppression, and levelling of load. As per the publishers, the quantity of mentions active and reactive current produced by the D- STATCOM can be calculated in a range of methods.

\section{BENEFITS OF DSTATCOM:}

The following are the fore most benefits of using DSTATCOM:

A DSTATCOM has a fast step response of 8 milli-seconds to 30 milli-seconds, that also helps with system stability administration. Within a DSTATCOM, active power regulation is also possible, that also facilitates in mechanism stability control. Over a large voltage variety, highly efficient and high reactive current are achieved. Improved dynamics, no rigidity, and lower functioning, capital, and cost of maintenance are all advantages of a synchronous condenser. Controlling voltage in both a static and dynamic manner. Comprehensive grid control is possible.

\section{APPLICATION OF DSTATCOM}

STATCOM regulates fundamental reactive power and provides voltage support at the transmission level, even though DSTATCOM regulates voltage and provides power factor correction at the distribution level.

A few of DSTATCOM's numerous implementations are as follows:

DSTATCOM provides protection of the power distribution system from voltage instability and flicker caused due to varying reactive current requirements. A DSTATCOM supplies leading or lagging reactive power to obtain stability of the system. The DSTATCOM allows for maximum-speed control of reactive power to compensate for voltage.

\section{CONCLUSION}

This review paper discusses a thorough analysis on DSTATCOM, and it was indicated that only by employing its pivotal short-term transient over-load functionality, DSTATCOM can minimize the dimension of the compensation scheme required to handle transient events. The short-term over-load capability is close to 325 percent for periods of 1 seconds to 3 seconds. The DSTATCOM controls physically moved capacitors in both transient and steady state to obtain the highest possible modification. DSTATCOM can also be utilized by utilities with unstable reactive loads or poor grid knots. It can carry unbalanced loads (including arc welding, vehicle crushers and shredders, and so on).

\section{REFERENCES}

[1] Sandeep Prajapati,Shivani Johri, "Power Quality Improvement using D-Statcom," International Journal of Emerging Technologies and Innovative Research,ISSN:2349-5162,Vol1, Issue 5,page no pp371379, October 2014

[2] Pallavi S, A Novel Adaptive Control for DSTATCOM by using ANN international Journal for Research in Engineering Application \& Management (IJREAM) ISSN : 2494-9150 Vol-01, Issue 12, MAR 2016

[3] Trupti P. Gulhane1, SVPWM Technique based D-STATCOM to Improve Power Quality in Distribution System International Research Journal of Engineering and Technology (IRJET) e Volume: 07 Issue: 01 | Jan 2020

[4] K. TANUJA1 Enhancement of Power Quality in Distribution System using D-Statcom ISSN 2348-2370 Vol.09,Issue.10, September-2017, Pages:1689-1694

[5] N.Ravendra1, V.Madhusudhan2, A.Jaya Laxmi3 "Modeling and Simulation of DSTATCOM for Power Quality Enhancement in Distribution System" International Journal of Advanced Research in Electrical, Electronics and Instrumentation Engineering, Vol. 5, Issue 6, June 2016.

[6] Prabhir Ranjan Kasari ; Nanish Paul "Analysis of D-STATCOM for power quality enhancement in distributed network" TENCON 20172017 IEEE Region 10 Conference,Penang,2017,pp. 1421-1426

[7] M. G. Molina and P. E. Mercado, Dynamic Modelling and Control Design of DSTATCOM with Ultra-Capacitor Energy Storage for Power Quality Improvements, Conference on Transmission and Distribution conference and Exposition: Latin America, IEEE/PES, pp. $18,2008$.

[8] Virulkar, V, and Aware, M, Analysis of DSTATCOM with BESS for mitigation of flicker, International Conference on Control, Automation, Communication and Energy Conservation, 2009. INCACEC 2009, 4-6 June 2009.

[9] Sepulveda, C.A, Espinoza, J.R., Landaeta, L.M., and Baier, C.R. Operating Regions Comparison of VSC-based Custom Power Devices, 32nd Annual Conference on IEEE Industrial Electronics, IECON 2006, 6-10 Nov. 2006.

[10] Naetiladdanon Sumate, Voltage Sag Compensation Performance by DSTATCOM with Series Inductor and Energy Storage, 7th International Conference on Power Electronics and Drive Systems, 2007. PEDS '07, 27-30 Nov. 2007. 
[11] Aodsup, K., Boonchiam, P.N., Sode-Yome, A., Kongsuk, P. and Mithulananthan, N. Response of DSTATCOM under Voltage Flicker in Farm Wind, 7th International Conference on Power Electronics and Drive Systems, 2007. PEDS '07, 27-30 Nov. 2007 